\title{
Fish muscle: the exceptional case of notothenioids
}

\author{
Daniel A. Fernández · Jorge Calvo
}

Received: 23 February 2008/ Accepted: 13 October 2008

(C) Springer Science+Business Media B.V. 2008

\begin{abstract}
Fish skeletal muscle is an excellent model for studying muscle structure and function, since it has a very well-structured arrangement with different fiber types segregated in the axial and pectoral fin muscles. The morphological and physiological characteristics of the different muscle fiber types have been studied in several teleost species. In fish muscle, fiber number and size varies with the species considered, limiting fish maximum final length due to constraints in metabolites and oxygen diffusion. In this work, we analyze some special characteristics of the skeletal muscle of the suborder Notothenioidei. They experienced an impressive radiation inside Antarctic waters, a stable and cold environment that could account for some of their special characteristics. The number of muscle fibers is very low, 12,700-164,000, in comparison to 550,000-1,200,000 in Salmo salar of similar sizes. The size of the fibers is very large, reaching $600 \mu \mathrm{m}$ in diameter, while for example Salmo salar of similar sizes have fibers of $220 \mu \mathrm{m}$ maximum diameter. Evolutionary adjustment in cell cycle length for working at low temperature has been shown in Harpagifer antarcticus $\left(111 \mathrm{~h}\right.$ at $\left.0^{\circ} \mathrm{C}\right)$, when compared to the closely related sub-Antarctic species Harpagifer bispinis $\left(150 \mathrm{~h}\right.$ at $\left.5^{\circ} \mathrm{C}\right)$. Maximum muscle
\end{abstract}

D. A. Fernández $(\bowtie) \cdot$ J. Calvo

Austral Center for Scientific Research (CADIC-

CONICET), 200 B. Houssay, CC 92 CADIC,

9410 Ushuaia, Tierra del Fuego, Argentina

e-mail: dfernandez@cadic.gov.ar fiber number decreases towards the more derived notothenioids, a trend that is more related to phylogeny than to geographical distribution (and hence water temperature), with values as low as 3,600 in Harpagifer bispinis. Mitochondria volume density in slow muscles of notothenioids is very high (reaching 0.56) and since maximal rates of substrate oxidation by mitochondria is not enhanced, at least in demersal notothenioids, volume density is the only means of overcoming thermal constraints on oxidative capacity. In brief, some characteristics of the muscles of notothenioids have an apparent phylogenetic component while others seem to be adaptations to low temperature.

Keywords Fish muscle - Muscle growth · Fiber size $\cdot$ Notothenioids $\cdot$ Temperature

\section{Introduction}

Notothenioids (Perciforms) are indigenous fish from the southern hemisphere. They are thought to have evolved from a temperate small benthic ancestor and have radiated very rapidly in the subzero waters of the Antarctic (Eastman 1993), sometime between $24 \mathrm{Ma}$ (million years ago) (Near 2004) and $7 \mathrm{Ma}$ (Bargelloni et al. 2000), according to dissimilar molecular clock estimations. The absence of an undisputed fossil makes the molecular clock calibration very inexact. This suborder is the best example of extensive 
radiation in a marine fish group (Eastman and Eakin 2000) and can be considered a species flock similar to the Cottoid species flock from Lake Baikal (Eastman and McCune 2000). The key physiological feature that allowed the notothenioids to diversify and become dominant in the fish fauna of the Southern Ocean was, almost certainly, the development of antifreeze glycoproteins (AFGPs) (Cheng and DeVries 1991; Eastman 1993). The key ecological feature that permitted the diversification of the suborder was probably the weak competition notothenioids experienced in Antarctic shallow waters due to the extinction events associated with the cooling conditions and the isolation of Antarctica (Eastman 1993). Although buoyancy modification that allowed notothenioids to occupy distinct positions in the water column was also appreciated as an important factor for the radiation, this trait seems to have evolved only once in notothenioids, and it is also not very common in the suborder, with only three species so far proven to be neutrally buoyant (Eastman and De Vries 1982; Balushkin 2000; Eastman and Sidell 2002; Near et al. 2004; Eastman 2005; Near et al. 2007). Today, notothenioids encompass a total of 44 genera and 129 species, 101 Antarctic and 28 non-Antarctic, the latter living in the Beagle Channel, Patagonian Shelf, along the Pacific Coast of South America, and in the subAntarctic waters of New Zealand (Eastman 2005).

\section{Fish axial muscle formation}

In fish, the skeletal muscles of the trunk and limb are derived from the somites. These repetitive structures are formed in a rostral-to-caudal sequence from the paraxial mesoderm, and their number varies greatly in fish, from 26 in the platy fish to more than 200 in some eels (Richardson et al. 1998). Recent works on zebrafish have proved the existence of a dermamyotome in fish (similar to the one described for amniotes) that is formed from the ABC cells (anterior border cells) of the somite through a "somite rotation" movement. These $\mathrm{ABC}$ cells will give rise to muscle fibers of the primary myotome and the dermamyotome, that will subsequently give rise to muscle precursors for the axial and fin muscles, and probably other cell types of the somite (Hollway and Currie 2005; Stellabotte and Devoto 2007; Stellabotte et al. 2007). The first functional fibers of the somites (primary myotome) elongate before the formation of the dermamyotome. Further growth in the myotome could occur by the ingression of these "external cells" into the myotome through the external layer of slow muscle cells (Stellabotte and Devoto 2007). "External cells" have been previously described in other teleost species (Johnston 1993; Stoiber and Sanger 1996), and therefore the mechanism described for zebrafish could be a common one for teleosts. More data on different teleost species are needed in order to asses the importance of this mechanism.

Muscle fiber types: axial

More than $60 \%$ of the body weight in fish can be muscle. This is only possible due to the minimal requirement of skeletal structure to support the weight of the body in water, and because of the need for a larger amount of muscle to power swimming in a denser medium like water (Bone 1978; Johnston 1981). The spatial arrangement of adult fish muscle, with different muscle fiber types located in discrete areas, allows a detailed analysis of its structure and function. Axial musculature is formed mainly by two different muscle fiber types, the white fibers and the red fibers, but there are also other fiber types (intermediate, tonic, red muscle rim fibers, etc.). The largest part of the axial musculature is white muscle, about $90 \%$ versus $10 \%$ of the rest of the fibers (mainly red) in several species of sub-Antarctic notothenioids analyzed (Fernández, unpublished results), falling within the range typically observed in other teleost species (Bone 1978). White and red muscle fiber types differ not only in their color, but also in many other important structural and physiological characteristics: innervation, blood supply, abundance of mitochondria, myoglobin content, energy storage, speed of contraction, fiber size, myosin isoforms, etc. Because of the different speed of their contractions, white fibers are also called "fast" and red fibers are called "slow" (Johnston 1981). From now on, we shall call them fast and slow, respectively.

Four different fiber types have been described for the axial muscles of nototheniods: slow, tonic, intermediate, and fast, using histochemical techniques for myosin ATPase, succinic dehydrogenase (SDHase), glycogen, and lipids (Walesby and Johnston 1980; Smialowska and Kilarski 1981; Dunn et al. 1989; Fernández 2000; Fernández et al. 2000). The different 


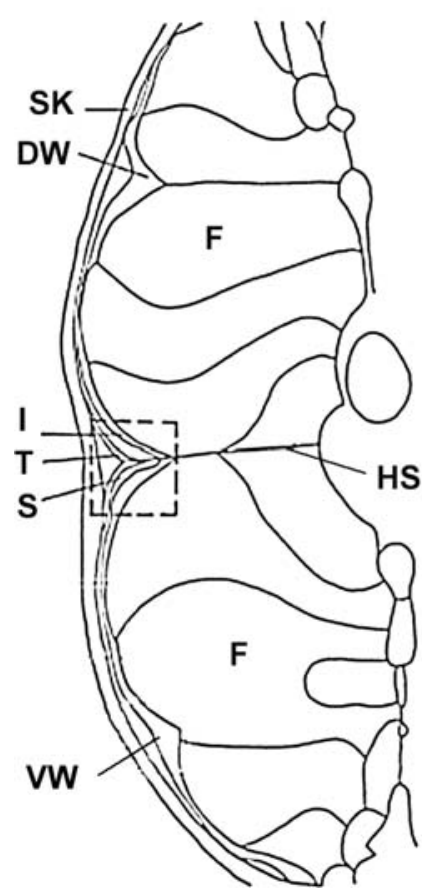

Fig. 1 Histochemistry of myotomal muscles in sub-Antarctic notothenioids. The box indicates the location of the main wedge, at the level of the horizontal septum $(H S)$, the place where all the pictures (a-d) have been taken (d shows only half of the main wedge), including the position of the different fiber types. a Champsocephalus esox (26 cm total length) stained for myosin ATPase following $90 \mathrm{~s}$ pre-incubation at $\mathrm{pH} 10 \cdot 6$. b Eleginops maclovinus $(10.3 \mathrm{~cm})$ stained for succinic

fiber types are relatively segregated in the myotome of notothenioids, with a superficial layer (the width varies in the different species) composed of tonic, slow, and intermediate fibers surrounding a core of fast fibers (see details in Fig. 1). A similar kind of segregation has been described for many other teleost species (Johnston et al. 1974; van Raamsdonk 1982; Rowlerson et al. 1985; Stoiber et al. 1998) and is strongly related to the needs for swimming. The fast fibers correspond to most of the muscle fibers in notothenioids, which makes sense since most species rely on burst-swimming, using the axial muscles, for predator-prey interactions. Pre-incubation at different $\mathrm{pHs}$ prior to staining for myosin ATPase can be used to characterize different fiber types when performed at room temperature in sub-Antarctic notothenioids (Fernández et al. 2000) and Antarctic ones (Fernández, unpublished data). The order of inactivation of the different fiber types with alkaline pre-incubation (for dehydrogenase activity. c Cottoperca gobio $(23 \mathrm{~cm})$ stained for glycogen. d Eleginops maclovinus $(37 \mathrm{~cm})$ stained for myosin ATPase at $\mathrm{pH} 9.5$ without pre-incubation. $T$ tonic muscle fibres, $S$ slow muscle fibres, $I$ intermediate muscle fibers, $F$ fast muscle fibres, $S K$ skin, $A$ adipocytes, $D W$ dorsal wedge, $V V$ ventral wedge. All scale bars $=100 \mu \mathrm{m}$. (From Fernández et al. 2000)

example, $\mathrm{pH} 10.4$ or $\mathrm{pH} 10.6$ ) in Notothenioids was fast $>$ intermediate $>$ slow (Fernández et al. 2000), different from the order found for temperate species which is slow $>$ fast $>$ intermediate. Therefore, in general, the $\mathrm{pH}$-sensitivity of the ATPase activity of fast muscle fibers in Antarctic and sub-Antarctic notothenioids was similar to that for slow muscle fibers in temperate or tropical species. However, Johnston (1987) measured the shortening speeds of live fiber bundles and demonstrated that the $\mathrm{SDH}^{+\mathrm{ve}}$ and $\mathrm{SDH}^{-\mathrm{ve}}$ muscle fibers in the Notothenioid Chaenocephalus aceratus corresponded to slow and fast twitch muscle fibers, respectively, as in other teleosts. The differences in the inactivation of the ATPases could indicate the existence of different myosin isoforms in notothenioids compared to other teleosts. Interestingly, Gauvry et al. (2000) found that there was a high level of similarity between the fast myosin of tropical species and the slow myosin of 
Antarctic species, comparing the amino acid sequence and the structure of ATPase binding sites.

\section{Pectoral fin muscles}

Fin muscles in teleosts are derived from the paraxial mesoderm, more specifically from the dermomyotome. Three of the four fiber types have been described for the pectoral fin muscles in sub-Antarctic notothenioids: tonic, slow, and fast (Fernández et al. 2000). The fiber type distribution in the abductor profundis muscle of all the species described was similar, comprising four different zones: (1) tonic: tonic fibers were found close to the pectoral girdle bones; (2) central region: a core of slow muscle fibers; (3) mosaic region: an area of slow muscle fibers intermingled with fast; and (4) peripheral region: an area of fast fibers occupying the more external part of the muscle (Fig. 2). Even though the distribution of the fiber types was very conserved in all the species, there was a consistent variation of the proportion of the different zones from the proximal to the distal ends of the muscle (Fernández et al. 2000). A similar zonation has also been found in Antarctic nototheniods (Walesby and Johnston 1980; Davison and MacDonald 1985; Harrison et al. 1987) and in other teleosts (Patterson et al. 2007; Devincenti et al. 2008). While slow muscle fibers are abundant in notothenioids, leaving an external marginal location to the fast fibers, the opposite situation is observed in the other teleosts studied. This fact is very likely related to the importance of labriform swimming (using pectoral fin muscles) in notothenioids in comparison with carangiform or subcarangiform swimming in the other species studied.
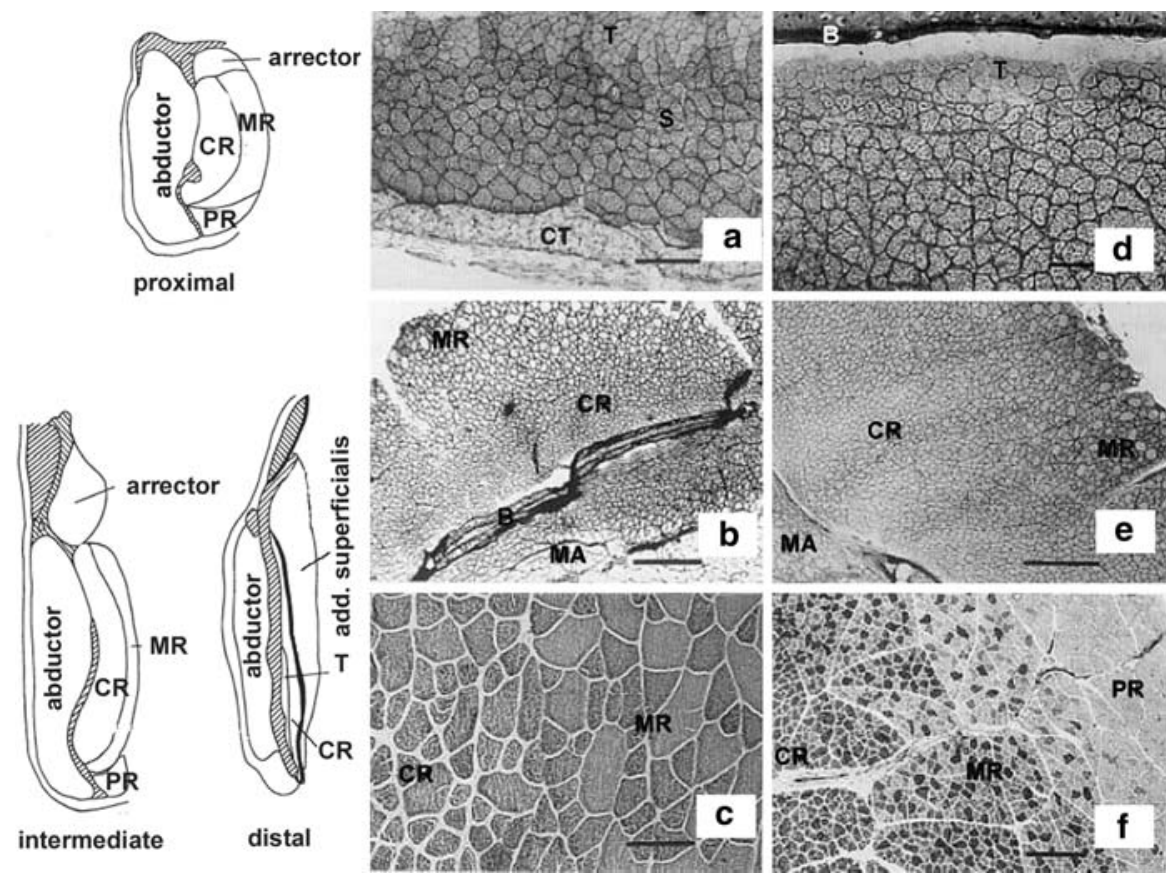

Fig. 2 Histochemical staining characteristics of the pectoral fin adductor muscle of P. tessellata $(\mathbf{a}-\mathbf{c})$ and E. maclovinus $(\mathbf{d}-\mathbf{f})$. The drawings indicate the location of the different regions of the adductor profundis muscle and the other muscles that form the pectoral musculature at the proximal, intermediate and distal ends of the muscles. a Tonic fibers $(T)$ are adjacent to the girdle bones (top), the slow muscle fibers compose the central region $(C R)$ at all levels of the pectoral muscles and the connective tissue $(C T)$ separates adductor profundis from adductor superficialis muscles (distal); (b) the $C R$ and the mosaic regions $(M R)$ are clearly distinguished because the latest has slow and fast muscle fibers intermingled (proximal); (c) detail of the $C R$ and $M R$ stained for mATPase following alkaline $(\mathrm{pH} \mathrm{10.6;90} \mathrm{s)} \mathrm{preincubation;} \mathrm{(d)} \mathrm{narrow}$ band of $T$ adjacent to the bone; (e) $C R$ and $M R$ in E. maclovinus (proximal) (f) spectacular mosaic in large E. maclovinus adductor muscle in a section stained for mATPase following alkaline $(\mathrm{pH} 10.6 ; 90 \mathrm{~s})$ preincubation; the peripheral region $(P R)$ can also be observed in the right top of the picture (intermediate). $S$ Slow muscle fiber, $B$ bone. Scale bar represents $100 \mu \mathrm{m}$ (a), (c), and (d) and $400 \mu \mathrm{m}(\mathbf{b})$, (e), and (f). (From Fernández et al. 1999, 2000) 
Muscle growth

Muscle growth occurs by two main processes, the addition of new fibers (hyperplasia) and the increase in size of existing fibers (hypertrophy). Muscle growth in fish differs from other vertebrates because it occurs indeterminately, due to continuous growth through life (Mommsen 2001). Four main phases of muscle growth occur in teleosts: one embryonic and three post-embryonic, but not all phases are present in each fish species (reviewed in Johnston 2003; Rowlerson and Veggetti 2001). Postembryonic growth phases are called stratified hyperplasia, mosaic hyperplasia, and hypertrophy, depending on the main process that is taking place at a given time. The final size of a given species is strongly regulated by the duration of the hyperplastic phases, since those phases determine the final number of muscle fibers. The final number of fibers restrains the final size of the species, given that the maximum size of a given fiber has physiological constraints, probably due to limitations in diffusion rates.

\section{Axial muscle fiber diameter}

The axial muscle of the notothenioids is unusual in containing very large diameter muscle fibers in comparison to other teleosts (Smialowska and Kilarski 1981; Dunn et al. 1989; Battram and Johnston 1991; Fernández et al. 2000; Johnston et al. 2003b). The maximum fiber diameters increase linearly with standard length, reaching more than $500 \mu \mathrm{m}$ in many of the species studied (Johnston et al. 2003b). Similar fiber diameter values were found in the light fibers of the blue crab Callinectes sapidus (Boyle et al. 2003). In general terms, muscle fibers are limited in size to promote short maximal intracellular diffusion distances in order to facilitate both rapid $\mathrm{O}_{2}$ flux to mitochondria and ATP flux from mitochondria to sites of ATP demand. Therefore, excessive cell size reduces the capacity for critical oxidative metabolic processes (Egginton and Sidell 1989; Boyle et al. 2003; Johnston et al. 2003b; Kinsey et al. 2005). One way of overcoming this problem, found in fish and crustaceans, is the redistribution of intracellular metabolic machinery over the course of development in order to reduce the diffusion distances between small blood vessels and mitochondria, something that has been documented in the burst swimming muscle of blue crab Callinectes sapidus (Boyle et al. 2003) and black sea bass Centropristis striata (Nyack et al. 2007). Small white muscle fibers have mitochondria evenly distributed throughout the fiber (intermyofibrillar mitochondria), while in large white muscle fibers the mitochondria become increasingly clustered at the periphery of the cell (subsarcolemmal mitochondria) and are much less densely distributed in the fiber interior. However, the redistribution increases the intracellular diffusive distances between mitochondrial clusters, which may greatly slow ATP diffusive flux (Boyle et al. 2003; Nyack et al. 2007). The burst fibers of fish and crustaceans rely on endogenous fuels to power a series of rapid contractions, being independent of the transport of either $\mathrm{O}_{2}$ to the mitochondria or ATP/phosphagen from mitochondria to cellular ATPases. Therefore, the metabolic recovery after a series of burst contractions. but not the contractile process (anaerobic), is influenced by an increase in fiber size or changing mitochondrial distribution. This may have serious implications for the animal's survival if multiple events of burst contractions are needed, such as during repeated predator-prey interactions (Kinsey et al. 2007).

Johnston et al. (2004) proposed for fish that there is an optimal maximum fiber diameter, which reflects a trade-off between avoiding diffusional constraints and the need to minimize the costs of ion pumping, and called this idea the "optimal fiber size hypothesis". The surface/volume ratio of muscle fibers, and therefore the maintenance of ionic homeostasis, that constitutes $20-40 \%$ of the resting metabolic rate in teleosts (Jobling 1995), decreases with increasing fiber diameter. It would therefore be beneficial that muscle fibers reach a size that is just below that which would be diffusion limited.

Axial muscle fiber number

Notothenioids, in general, have low muscle fiber numbers (Battram and Johnston 1991). Eleginops maclovinus, for example, a notothenioid with an unusually large number of fibers, has only 164,000 fibers in contrast to 1,200,000 fibers in an Atlantic salmon Salmo salar of similar size (Johnston et al. 2003b). Phylogenetic independent contrast analysis in notothenioids showed that fiber number differs significantly between species that belong to the more basal and the most derived families, suggesting a 
decreasing trend in fiber numbers during the evolution of the suborder. Moreover, the decrease in the number of fibers correlates with an increase in the diameter of the fibers (Johnston et al. 2003b). On the other hand, there is no evident relationship between the geographical zone of origin (Antarctic vs sub-Antarctic) and the maximum fiber diameter of the species. Therefore, the special traits of Notothenioid muscle (low fiber number and giant fiber size) have an important phylogenetic component, apart from the well-established relationship between low temperature and large fiber diameter.

The main phases in post-embryonic muscle growth are stratified and mosaic hyperplasia. Some species lack mosaic hyperplasia, and thus the final number of fibers is greatly reduced. Mosaic hyperplasia is absent in all the species of the more derived families already studied (Harpagiferidae and Channichthyidae), giving a clue about how muscle fiber number has been adjusted during the evolution of this suborder (Johnston et al. 2003b).

Muscle growth and temperature

The main process involved in muscle growth of notothenioids, hypertrophy, has been studied in adult Harpagifer antarcticus (Antarctic) and Harpagifer bispinis (sub-Antarctic) acclimated at summer and winter temperatures (Brodeur et al. 2003a, b). These species are very good models for studying hypertrophy, since hyperplasia has completely stopped in adult fish (Johnston et al. 2003a). Cell cycle times were estimated for $\mathrm{H}$. bispinis at $10^{\circ} \mathrm{C}(81.3 \mathrm{~h})$ and $5^{\circ} \mathrm{C}$ $(150 \mathrm{~h})$, with $Q_{10}=3.4$, and $\mathrm{H}$. antarcticus at $0^{\circ} \mathrm{C}$ $(111 \mathrm{~h})$. The longer duration of the cell cycle at $5^{\circ} \mathrm{C}$ in $H$. bispinis than at $0^{\circ} \mathrm{C}$ in $H$. antarcticus indicates the existence of a cold compensation in the Antarctic species, allowing a substantial reduction in the time of the cell cycle progression rate at low temperatures. The predicted cell cycle time for $\mathrm{H}$. bispinis at $0^{\circ} \mathrm{C}$ (based on the $Q_{10}$ relationship) would be $227 \mathrm{~h}$, more than double the value found for $H$. antarcticus.

Brodeur et al. (2003b) found evidence of a direct stimulation of myogenic cell activation by feeding at two different temperatures (about a two-fold increase in the cells that express the surface protein c-met that seems to be involved in their activation; Cornelison and Wold 1997) in H. bispinis. The number of myogenic cells generated in response to feeding did not appear to be directly related to temperature. The main difference between the responses to feeding of fish acclimatized to simulated winter and summer conditions resided in the expression of myogenin, which was much less pronounced in summer. Interestingly, the delay between the ingestion of the meal and the activation of the myogenic progenitors (cells that express the surface protein c-met that seems to be involved in their activation; Cornelison and Wold 1997) in $H$. bispinis was shorter than the cell cycle duration estimated for both summer and winter temperatures (150 and $81 \mathrm{~h}$, respectively). This result could indicate either that the cell cycle progression rate is accelerated by feeding, or that a proportion of the activated cells were stopped at a checkpoint in the cell cycle, and therefore could divide faster after activation since they had already progressed through part of the cell cycle (Walworth 2000). The latter is in agreement with previous results on Notothenia coriiceps suggesting that myogenic cells activated by feeding were cells stopped at the G1/S checkpoint of the cell cycle (Brodeur et al. 2002).

Antarctic and sub-Antarctic notothenioids, adapted to living at very low temperatures, have abundant mitochondria in the slow muscle fibers (Johnston 1987; Londraville and Sidell 1990). For example, reported mitochondrial volume density values of slow muscle fibers were 0.56 for Pleuragramma antarcticum (Johnston et al. 1988) and 0.51 for Champsocephalus esox (Johnston et al. 1998), amongst the highest recorded for vertebrates. Nevertheless, different lifestyles of the species may confound the relationship between temperature and mitochondria volume densities. For example, Sanger et al. (2005) found a significant difference in the mitochondrial content in all the skeletal muscles sampled from Pagothenia borchgrevinki (cryopelagic) and Trematomus bernacchii (benthic). Johnston et al. (1998) found a significant inverse relationship between mitochondrial volume density in slow muscle and habitat temperature in a research restricted to demersal and moderately active species (Fig. 3).

Diverse adaptive explanations have been proposed to account for this fact, including the hypothesis that increases in mitochondrial volume density partially compensate for the reduced catalytic capacity at low temperatures (Johnston 1982; Egginton and Sidell 1989) or otherwise compensate for the reduced diffusion coefficients of cytosolic metabolites (Tyler and Sidell 1984; Sidell and Hazel 1987). The same 


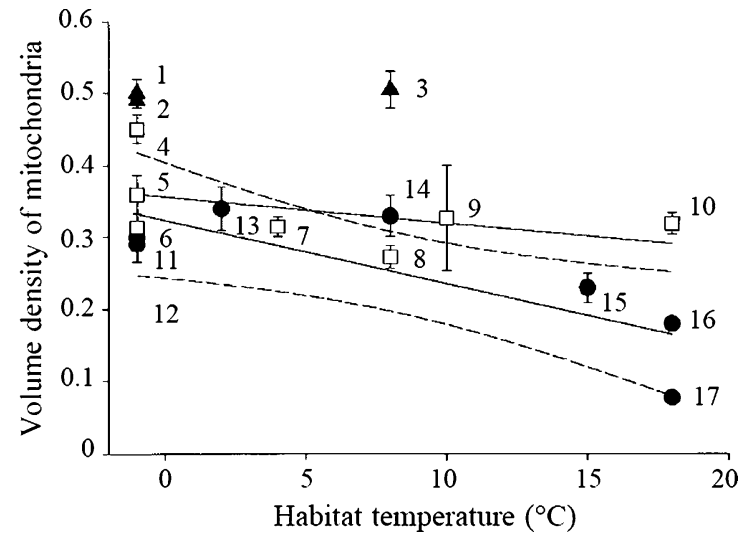

Fig. 3 Relationship between the volume density of mitochondria and habitat temperature for red pectoral fin adductor muscle fibres in perciform fish. Filled triangles are Channichthyidae, open squares are active pelagic species, and filled circles are a combination of demersal or only moderately active mid-water species. Values represent means \pm SEM. Species: 1 Chaenocephalus aceratus, 2 Champsocephalus gunnari, 3 Champsocephalus esox, 4 Psilodraco breviceps, 5 Notothenia coriiceps, 6 Trematomus newnesi, 7 winter-caught Eleginops maclovinus, 8 summer-caught Eleginops maclovinus, 9 Paranotothenia magellanica, 10 Coris julius, 11 Notothenia gibberifrons, 12 Lepidonotothen nudifrons, 13 Notothenia rossii, 14 Patagonotothen tessellata, 15 Callionymus lyra, 16 Lithognathus mormyrus, 17 Serranus cabrilla. The lines represent linear regressions and 95\% confidence limits. For the species classified as less active (solid line with dashed lines representing the $95 \%$ confidence limits), the equation was $V \mathrm{v}(\mathrm{mt})=0.33-0.0088 T$, where $V \mathrm{v}(\mathrm{mt})$ is the volume density of mitochondria and $T$ is habitat temperature; adjusted $r^{2}=0.64 ; P=0.03$. There was no significant relationship between mitochondrial volume density and habitat temperature for the species classified as active/pelagic, the equation was $V \mathrm{v}(\mathrm{mt})=0.35-0.0036 T$; adjusted $r^{2}=0.22$, $P=0.31$. (From Johnston et al. 1998)

adaptive explanations proposed for cold-acclimation may apply to fish living at low temperatures like notothenioids, with increased volume and surface density of mitochondrial clusters as the main mechanism for enhancing the aerobic capacity of muscle in cold-water species (Johnston et al. 1998). Volume density values in the icefish are much higher than in red-blooded nototheniods, something that would be expected in species that lack haemoglobin and myoglobin, the common oxygen carriers (Guderley 2004). The cell membrane phospholipids composition changes markedly, probably to maintain membrane fluidity in distinct thermal habitats, by modifications in the unsaturation and the proportions of long chain polyunsaturated fatty acids, and the relative levels of different phospholipid head groups in acclimated fish
(Cossins et al. 1977; Hazel and Williams 1990). The increased unsaturation of membranes from coldadapted fish is likely to increase proton leak, producing oxygen uptake without ATP synthesis, during mitochondrial substrate oxidation, and to make the membranes more susceptible to peroxidation by reactive oxygen species ROS. At least $20 \%$ of standard metabolic rate is dedicated to proton leak (Rolfe and Brand 1996; Rolfe et al. 1999), but proton leak reduces the potential across the inner mitochondrial membrane, reducing the production of ROS, which could be adaptive for fish living in cold waters.

\section{Swimming}

Fish use fast-starts to escape predators and to capture prey, and therefore this behavior is important for survival. Escape responses have been analyzed in the sub-Antarctic notothenioid Eleginops maclovinus tested at $2-10^{\circ} \mathrm{C}$ and showed an overall dependence on temperature, with the most common parameters used to evaluate escape responses (velocity, acceleration, and power output) varying significantly with temperature and being at a maximum at $8^{\circ} \mathrm{C}$, with $Q_{10}$ values of $1.90,3.27$, and 8.90 , respectively (Fernández et al. 2002). In contrast, escape swimming velocity was almost thermal independent for the Antarctic notothenioids Trematomus bernachii and T. centronotus tested between -1 and $10^{\circ} \mathrm{C}$, and this was interpreted as evidence for cold adaptation of performance (Wilson et al. 2001).

The curvature of the body during the escape response $(\hat{c})$ decreased with increasing temperature in E. maclovinus (Fernández et al. 2002) being within the range for temperate species reported in the literature (Wakeling and Johnston 1998; Wakeling et al. 2000). In contrast, several Antarctic notothenioids were found to flex their body to a much greater degree during fast-starts (Wakeling and Johnston 1998). Therefore, the curvature of the body during the escape response is a good candidate for a specialised adaptation to cold conditions in notothenioids.

\section{Conclusions}

Muscle fibers of notothenioids are less numerous and bigger in size than other fish species, and show a clear 
trend to reduction in number and increase in size from the ancestral to the more derived notothenioids, but not a geographical pattern. Mitochondria volume densities in slow muscles of notothenioids are very high, being likely an adaptation to low temperature. Antarctic notothenioids also show evidence of an evolutionary adjustment to temperature in cell cycle length. Muscle fibers in notothenids may have evolved to be as large as possible without experiencing diffusion limitations in order to minimize the sarcolemmal membrane area over which membrane potential must be maintained. This would make sense since it would reduce the costs of ionic homeostasis, which is a considerable fraction of basal metabolic rate. It is not clear if swimming in notothenioids is more influenced by phylogeny or by temperature, since different parameters show different trends.

In brief, some characteristics of the muscles of nototheniods seem to have a prevalent phylogenetic component while others seem to be adaptations to low temperature.

Acknowledgments We would like to thank CONICET, Agencia de Investigación Científica y Tecnológica (SeCyT), Fundación Antorchas and the European Union for funding previous projects on muscle of notothenioids. We would also like to thank present and past members of the laboratory of Ecophysiology at CADIC for collaboration in these projects. Sandy Becker and Sheryl Macnie helped to improve the English of the manuscript. Comments from two anonymous referees have helped greately to improve the manuscript.

\section{References}

Balushkin A (2000) Morphology, classification, and evolution of notothenioid fishes of the Southern Ocean (Notothenioidei, Perciformes). J Ichthyol 40:S74-S109

Bargelloni L, Marcato S, Zane L et al (2000) Mitochondrial phylogeny of notothenioids: a molecular approach to Antarctic fish evolution and biogeography. Syst Biol 49:114-129. doi:10.1080/10635150050207429

Battram JC, Johnston IA (1991) Muscle growth in the Antartic teleost, Nothothenia neglecta (Nybelin). Antarct Sci 3:2933. doi:10.1017/S0954102091000068

Bone Q (1978) Locomotor muscle. In: Hoar WS, Randall DJ (eds) Fish physiology, vol 7. Academic Press, New York, pp 361-424

Boyle KL, Dillaman RM, Kinsey ST (2003) Mitochondrial distribution and glycogen dynamics suggest diffusion constraints in muscle fibers of the blue crab, Callinectes sapidus. J Exp Zoolog A Comp Exp Biol 297:1-16

Brodeur JC, Peck L, Johnston IA (2002) Feeding increases MyoD and PCNA expression in myogenic progenitor cells of Notothenia coriiceps. J Fish Biol 60:1475-1485
Brodeur JC, Calvo J, Clarke A et al (2003a) Myogenic cell cycle duration in Harpagifer species with sub-Antarctic and Antarctic distributions: evidence for cold compensation. J Exp Biol 206:1011-1016. doi:10.1242/jeb.00204

Brodeur JC, Calvo J, Johnston IA (2003b) Proliferation of myogenic progenitor cells following feeding in the subAntarctic notothenioid fish Harpagifer bispinis. J Exp Biol 206:163-169. doi:10.1242/jeb.00052

Cheng CC, DeVries AL (1991) The role of antifreeze glycopeptides and peptides in the freezing avoidance of coldwater fish. In: Prisco Gd (ed) Life under extreme conditions. Springer, Berlin Heidelberg New York, pp 1-14

Cornelison D, Wold B (1997) Single-cell analysis of regulatory gene expression in quiescent and activated mouse skeletal muscle satellite cells. Dev Biol 191:270-283. doi:10.1006/ dbio.1997.8721

Cossins AR, Friedlander MJ, Prosser CL (1977) Correlations between behavioral temperature adaptations of goldfish and the viscosity and fatty acid composition of their synaptic membranes. J Comp Physiol [A] 120:109. doi:10.1007/BF00 619309

Davison W, MacDonald JA (1985) A histochemical study of the swimming musculature of Antartic fish. NZ J Zool 12:473-483

Devincenti CV, Díaz AO, Garcïa AM et al (2008) Pectoral fins of Micropogonias furnieri: a histochemical and ultrastructural study. Fish Physiol Biochem. doi:10.1007/ s10695-008-9216-3

Dunn JF, Archer SD, Johnston IA (1989) Muscle fibre types and metabolism in post-larval and adult stages of Notothenoid fish. Polar Biol 9:213-223. doi:10.1007/BF00 263769

Eastman JT (1993) Antarctic fish biology: evolution in an unique environment. Academic Press, New York

Eastman JT (2005) The nature of the diversity of Antarctic fishes. Polar Biol 28:93-107. doi:10.1007/s00300-0040667-4

Eastman JT, De Vries AL (1982) Buoyancy studies of Notothenioid fishes in McMurdo Sound, Antractica. Copeia 2:385-393. doi:10.2307/1444619

Eastman JT, Eakin R (2000) An updated species list for notothenioid fish (Perciformes; Notothenioidei), with comments on Antarctic species. Arch Fisch Meeresforsch 48:11-20

Eastman JT, McCune A (2000) Fishes on the Antarctic continental shelf: evolution of a marine species flock? J Fish Biol 57:84-102

Eastman JT, Sidell BD (2002) Measurements of buoyancy for some Antarctic notothenioid fishes from the South Shetland Islands. Polar Biol 25:753-760

Egginton S, Sidell BD (1989) Thermal acclimation induces adaptive changes in subcellular structure of fish skeletal muscle. Am J Physiol 256:1-9

Fernández DA (2000) Caracterización histoquimica, distribución y crecimiento de las fibras musculares en Nototenidos subantárticos. Análisis inicial de dos factores relacionados con la natación: flotabilidad y temperatura. Biology Department. Universidad de Buenos Aires, Buenos Aires

Fernández DA, Calvo J, Johnston IA (1999) Characterisation of the swimming muscles of two sub-Antarctic Notothenioids. Sci Mar 201:477-484 
Fernández DA, Calvo J, Franklin CE et al (2000) Muscle fibre types and size distribution in sub-antarctic notothenioid fishes. J Fish Biol 56:1295-1311. doi:10.1111/j.10958649.2000.tb02144.x

Fernández DA, Calvo J, Wakeling JM et al (2002) Escape performance in the sub-Antarctic notothenioid fish Eleginops maclovinus. Polar Biol 25:914-920

Gauvry L, Ennion S, Ettelaie C et al (2000) Characterisation of red and white muscle myosin heavy chain gene coding sequences from Antarctic and tropical fish. Comp Biochem Physiol B 127:575-588. doi:10.1016/S0305-0491 (00)00286-8

Guderley H (2004) Metabolic responses to low temperature in fish muscle. Biol Rev Camb Philos Soc 79:409-427. doi: 10.1017/S1464793103006328

Harrison P, Nicol CJM, Johnston IA (1987) Gross morphology, fibre composition and mechanical properties of pectoral fin muscles in the Antartic teleost Notothenia neglecta Nybelin. Proceedings of the V Congress of European Ichthyology, Stockholm, pp 459-465

Hazel JR, Williams EE (1990) The role of alterations in membrane lipid composition in enabling physiological adaptation of organisms to their physical environment. Prog Lipid Res 29:167-227. doi:10.1016/0163-7827(90) 90002-3

Hollway G, Currie P (2005) Vertebrate myotome development. Birth Defects Res C Embryo Today 75:172-179. doi: 10.1002/bdrc.20046

Jobling M (1995) Fish bioenergetics. Chapman \& Hall, London Johnston IA (1981) Structure and function of fish muscle. Symp Zool Soc Lond 48:71-113

Johnston IA (1982) Capillarisation, oxygen diffusion distances and mitochondrial content of carp muscles following acclimation to summer and winter temperatures. Cell Tissue Res 222:325-337. doi:10.1007/BF00213216

Johnston IA (1987) Respiratory characteristics of muscle fibres in a fish (Chaenocephalus aceratus) that lacks haem pigments. J Exp Biol 133:415-428

Johnston IA (1993) Temperature influences muscle differentiation and the relative timing of organogenesis in herring (Clupea harengus) larvae. Mar Biol (Berlin) 116:363379. doi:10.1007/BF00350053

Johnston IA (2003) Muscle metabolism and growth in Antarctic fishes (suborder Notothenioidei): evolution in a cold environment. Comp Biochem Physiol B Biochem Mol Biol 136:701-713. doi:10.1016/S1096-4959(03)00258-6

Johnston IA, Patterson S, Ward W et al (1974) The histochemical demonstration of myofibrillar adenosine triphosphatase activity in fish muscle. Can J Zool 52:871877. doi:10.1139/z74-118

Johnston IA, Camm JP, White M (1988) Specialisations of swimming muscles in the pelagic Antarctic fish Pleuragramma antarcticum. Mar Biol 100:3-12. doi:10.1007/ BF00392949

Johnston IA, Calvo J, Guderley H et al (1998) Latitudinal variation in the abundance and oxidative capacities of muscle mitochondria in perciform fishes. J Exp Biol 201:1-12

Johnston I, Vieira VL, Fernandez DA et al (2003a) Muscle growth in Polar fish: a study of Harpagifer species with sub-Antarctic and Antarctic distributions. Fish Sci 68:1023-1028
Johnston IA, Fernández DA, Calvo J et al (2003b) Reduction in muscle fibre number during the adaptive radiation of notothenioid fishes: a phylogenetic perspective. J Exp Biol 206:2595-2609. doi:10.1242/jeb.00474

Johnston IA, Abercromby M, Vieira VL et al (2004) Rapid evolution of muscle fibre number in post-glacial populations of Arctic charr Salvelinus alpinus. J Exp Biol 207:4343-4360. doi:10.1242/jeb.01292

Kinsey ST, Pathi P, Hardy KM et al (2005) Does intracellular metabolite diffusion limit post-contractile recovery in burst locomotor muscle? J Exp Biol 208:2641-2652. doi: 10.1242/jeb.01686

Kinsey ST, Hardy KM, Locke BR (2007) The long and winding road: influences of intracellular metabolite diffusion on cellular organization and metabolism in skeletal muscle. J Exp Biol 210:3505-3512. doi:10.1242/jeb.000331

Londraville RL, Sidell BD (1990) Ultrastructure of aerobic muscle in Antarctic fishes may contribute to maintenance of diffusive fluxes. J Exp Biol 150:205-220

Mommsen TP (2001) Paradigms of growth in fish. Comp Biochem Physiol B Biochem Mol Biol 129:207-219. doi: 10.1016/S1096-4959(01)00312-8

Near TJ (2004) Estimating divergence times of notothenioid fishes using a fossil-calibrated molecular clock. Antarct Sci 16:37-44. doi:10.1017/S0954102004001798

Near TJ, Pesavento JJ, Cheng C-HC (2004) Phylogenetic investigations of Antarctic notothenioid fishes (Perciformes: Notothenioidei) using complete gene sequences of the mitochondrial encoded 16S rRNA. Mol Phylogenet Evol 32:881-891. doi:10.1016/j.ympev.2004.01.002

Near TJ, Kendrick BJ, William Detrich H et al (2007) Confirmation of neutral buoyancy in Aethotaxis mitopteryx DeWitt (Notothenioidei: Nototheniidae). Polar Biol 30:443-447. doi:10.1007/s00300-006-0201-y

Nyack AC, Locke BR, Valencia A et al (2007) Scaling of postcontractile phosphocreatine recovery in fish white muscle: effect of intracellular diffusion. Am J Physiol Regul Integr Comp Physiol 292:R2077-R2088. doi:10.1152/ajpregu. 00467.2006

Patterson SE, Mook LB, Devoto SH (2007) Growth in the larval zebrafish pectoral fin and trunk musculature. Dev Dyn 237:307-315. doi:10.1002/dvdy.21400

Richardson MK, Allen SP, Wright GM et al (1998) Somite number and vertebrate evolution. Development 125: $151-160$

Rolfe DF, Brand MD (1996) Contribution of mitochondrial proton leak to skeletal muscle respiration and to standard metabolic rate. Am J Physiol 271:C1380-C1389

Rolfe DF, Newman JM, Buckingham JA et al (1999) Contribution of mitochondrial proton leak to respiration rate in working skeletal muscle and liver and to SMR. Am J Physiol 276:C692-C699

Rowlerson A, Veggetti A (2001) Cellular mechanisms of postembryonic growth in aquaculture especies. In: Johnston IA (ed) Muscle development and growth. Academic Press, San Diego

Rowlerson A, Scapolo P, Mascarello E et al (1985) Comparative study of myosins present in the lateral muscle of some fish: species variations in myosin isoforms and their distribution in red, pink and white muscle. J Muscle Res Cell Motil 6:601-640. doi:10.1007/BF00711917 
Sanger AM, Davison W, Egginton S (2005) Muscle fine structure reflects ecotype in two nototheniids. J Fish Biol 66:1371-1386. doi:10.1111/j.0022-1112.2005.00689.x

Sidell BD, Hazel JR (1987) Temperature affects the diffusion of small molecules through cytosol of fish muscle. J Exp Zool 129:191-203

Smialowska E, Kilarski W (1981) Histological analysis of fibres in myotomes of Antarctic fish (Admiralty Bay, King George Islands, South Shetland Islands) I. Comparative analysis of muscle fibre sizes. Pol Polar Res 2:109-129

Stellabotte F, Devoto SH (2007) The teleost dermomyotome. Dev Dyn 236:2432. doi:10.1002/dvdy.21253

Stellabotte F, Dobbs-McAuliffe B, Fernández DA et al (2007) Dynamic somite cell rearrangements lead to distinct waves of myotome growth. Development 134:1253-1257. doi: $10.1242 /$ dev.000067

Stoiber W, Sanger AM (1996) An electron microscopic investigation into the possible source of new muscle fibres in teleost fish. Anat Embryol (Berl) 194:569-579. doi: 10.1007/BF00187470

Stoiber W, Haslett JR, Goldschmid A et al (1998) Patterns of superficial fibre formation in the European pearlfish $(R u$ tilus frisii meidingeri) provide a general template for slow muscle development in teleost fish. Anat Embryol 197:485-496. doi:10.1007/s004290050159
Tyler S, Sidell BD (1984) Changes in motochondrial disribution and diffusion distances in muscle of goldfish upon acclimation to warm and cold temperature. J Exp Zool 232:1-9. doi:10.1002/jez.1402320102

van Raamsdonk W (1982) Differentiation of the muscle fiber types in the teleost Brachydanio rerio, the zebrafish. Anat Embryol 164:51-62. doi:10.1007/BF00301878

Wakeling JM, Johnston IA (1998) Muscle power output limits fast-start performance in fish. J Exp Biol 201:1505-1526

Wakeling JM, Cole NJ, Kemp K et al (2000) The biomechanics and evolutionary significance of thermal acclimation in the common carp Cyprinus carpio. Am J Physiol Regul Integr Comp Physiol 279:657-665

Walesby NJ, Johnston IA (1980) Fibre types in locomotory muscles of an antarctic teleost Notothenia rosii. Cell Tissue Res 208:143-164. doi:10.1007/BF00234180

Walworth NC (2000) Cell-cycle checkpoint kinases: checking in on the cell cycle. Curr Opin Cell Biol 12:697-704. doi: 10.1016/S0955-0674(00)00154-X

Wilson R, Franklin C, Davison W et al (2001) Stenotherms at sub-zero temperature: thermal dependence of swimming performance in Antarctic fish. J Comp Physiol [B] 171:263-269. doi:10.1007/s003600000172 